\title{
AVALIAÇÃO DOS TEORES DE CHUMBO E AMÔNIA EM TINTURAS CAPILARES
}

Ariane Caroline Ribeiro, Lucas Willian Barbosa, Daniel Ângelo Macena, Vinícius Marques Gomes, Patrícia Alexandre Antunes

Universidade do Oeste Paulista - UNOESTE, Curso de Química Bacharelado, Presidente Prudente, SP. E-mail: luquinha willian@hotmail.com.

\section{RESUMO}

Observa-se que as tinturas progressivas contêm muitos produtos químicos, dentre eles a amônia, o peróxido de hidrogênio e metais potencialmente tóxicos, como chumbo, onde os seus limites permitidos deveriam ser informados nos rótulos. Por este motivo a análise de possíveis contaminantes é necessária para ajudar a garantir a saúde pública, quantificando e comparando com os dados apresentados não só nas embalagens, mas também na legislação vigente. Desta forma, este estudo pretende determinar os teores de chumbo e amônia, utilizando métodos clássicos da literatura como volumetria de neutralização com ácido forte e base fraca e gravimetria. A partir dos resultados obtidos concluiu-se que todas as amostras analisadas estão respeitando os limites impostos pela ANVISA não ultrapassando essa margem. No que diz respeito aos dados presentes nas embalagens, todas apresentaram a informação da presença de chumbo, porém a de amônia não constava no rótulo, pois seu teor estava abaixo dos $2 \%$.

Palavras-chave: Toxicidade. Tintura Progressiva. Gravimetria. Volumetria.

\section{EVALUATION OF LEAD LEVELS AND AMMONIA IN HAIR DYES}

\begin{abstract}
It is noted that progressive dyes contain many chemicals, among them ammonia, hydrogen peroxide and potentially toxic metals, such as lead, where their permitted limits should be reported on the labels. For this reason the analysis of possible contaminants is necessary to help ensure public health, quantifying and comparing with the data presented not only on the packaging but also in the current legislation. In this way, this study intends to determine the levels of lead and ammonia, using classic literature methods such as volumetric neutralization with strong acid and weak base and gravimetry. From the results obtained, it was concluded that all the analyzed samples are respecting the limits imposed by ANVISA not exceeding this margin. Regarding the data present on the packaging, all presented the information of the presence of lead, but the ammonia was not on the label, since its content was below $2 \%$.
\end{abstract}

Keywords: Toxicity. Progressive dye. Gravimetry. Volumetrics. 


\section{INTRODUÇÃO}

A arte de tingir os cabelos vem de milhares de anos atrás, desde a época dos egípcios, sendo comum o uso de sulfeto de chumbo, materiais orgânicos e principalmente a henna. $A$ mudança na cor dos cabelos é um desejo inerente dos seres humanos, porém as formas que encontraram para atender essa necessidade não foram viáveis, por oferecer riscos ao organismo.

Na mesma época em que August Wilhelm Von Hofmann estudou as propriedades da parafenilenodiamina (PFD), foi descoberto os benefícios do peróxido de hidrogênio, onde o mesmo apresentava menos danos aos fios (OLIVEIRA et al.,2014).

A marca mais conhecida nos dias atuais foi criada por Eugene Schueller, utilizando estes estudos do peróxido de hidrogênio. L'oréal foi a primeira tintura artificial comercializada (OLIVEIRA et al.,2014). As tinturas são classificadas em quatro tipos: Progressivas ou gradativas, permanentes, semipermanentes e temporárias.

Permanentes para conseguir o efeito esperado, as tinturas permanentes contêm componentes que penetram através da cutícula onde dependem de uma reação de oxidação, pois são soluções alcalinas (pH 9 a 10) á base de amônia (KEDE e SABATOVICH, 2009). A amônia tem a função de abrir as cutículas dos fios para que posteriormente o pigmento fixe no interior do cabelo (BARSANTI, 2009).

Nas tinturas semipermanentes existe baixa dosagem de peróxido de hidrogênio. A coloração ocorre apenas na parte externa dos cabelos, tingindo superficialmente sem alterar a estrutura dos fios, sendo eliminada gradativamente após cada lavagem. São usados para escurecer e nunca para clarear (BARSANTI, 2009). São corantes orgânicos, hidrossolúveis, de baixo peso molecular e livre de amônia logo não ocorre oxidação (KEDE \& SABATOVICH, 2009).

As tinturas temporárias atuam no exterior do cabelo, sem penetrá-lo, porém, geralmente são removidas na primeira lavagem. A tintura temporária mais conhecida é a Henna, tem como vantagem a fácil aplicação sem agredir os cabelos (KEDE e SABATOVICH, 2009).

As Progressivas ou gradativas utilizam corantes metálicos, como sais de chumbo, bismuto ou prata. Apenas escurece o tom natural do cabelo em tons limitados de negro, marrom ou cinza. A desvantagem está na irreversibilidade do processo (KEDE e SABATOVICH, 2009). O modo de ação desse tipo de tintura se baseia na deposição de sais metálicos como o acetato de chumbo sobre os cabelos, sendo uma deposição cumulativa, com interação entre a queratina da haste do fio e o metal (GOMES, 1999).

Anos após descobrirem uma forma de pintar os cabelos, as tintas atuais mesmo modificadas ainda contêm substâncias que podem nos prejudicar, porém há órgãos que fiscalizam o limite de cada substância presente na tintura. A Agência Nacional de Vigilância Sanitária (ANVISA) foi criada com o objetivo de assegurar a saúde da população por meio de controles sanitários da produção e comercialização de produtos além de fiscalizar o limite de cada substância presente na tintura (GOMES, 2013).

As tinturas progressivas contêm muitos produtos químicos, dentre eles a amônia o peróxido de hidrogênio e metais pesados, como chumbo. Para cada metal presente o limite máximo permitido é diferente (ANVISA, 2000).

No caso do Chumbo o limite permitido é de20 ppm, ou seja, o produto final não poderá ser superior a $0,6 \%$ estabelecidos na legislação vigente. Nessa concentração a absorção cutânea é baixa e é pouco provável apresentar riscos à saúde do usuário (ANVISA, 2000).

O peróxido de hidrogênio deve apresentar uma concentração de $12 \%$ do produto final, sendo 40 volumes. Em relação à amônia, deve-se apresentar no máximo 6\%, sendo obrigatório constar no rótulo acima de $2 \%$ (ANVISA, 2000).

Atualmente é comum as pessoas tingirem seus cabelos das mais variadas cores, tanto por estética, para esconder os fios brancos, quanto por moda, para seguir a tendência de cores 
diferentes. Por este motivo, o objetivo do estudo foi determinar o teor de chumbo e amônia em diferentes marcas de tinturas progressivas disponíveis no mercado.

\section{METODOLOGIA}

Foram escolhidas 6 marcas diferentes e tipos (gênero) de tinturas para se realizar a quantificação dos constituintes de interesse realizando 3 repetições do mesmo lote de cada amostra para minimizar possíveis erros.

Os resultados foram comparados com os rótulos (caso houvesse este tipo de informação) e com a legislação vigente. Optou-se por métodos clássicos, pois apresentam resultados mais exatos e precisos além de ser uma metodologia considerada de baixo custo.

\section{DETERMINAÇÃO DE AMÔNIA POR TITRIMETRIA}

Foi pesado uma quantidade de amostra que dispusesse aproximadamente $1,0 \mathrm{~g}$ de amostra em um erlenmeyer de $250 \mathrm{~mL}$. A esta massa pesada, foi adicionado $100 \mathrm{~mL}$ de água destilada e 3 gotas do indicador vermelho de metila.

Uma titulação de neutralização foi realizada utilizando como titulante ácido sulfúrico $1 \mathrm{~N}$, até o aparecimento da cor vermelha, indicando o ponto de equivalência da reação. (ANVISA - Guia de Controle de Qualidade de Produtos Cosméticos, 2007).

Os devidos cálculos foram realizados a partir da equação abaixo:

$$
C=\frac{V \times f c \times 1,703}{m}
$$

Onde:

$\mathrm{C}=$ concentração $(\mathrm{p} / \mathrm{p})$ de amônia $\left(\mathrm{NH}_{3}\right)$

$\mathrm{V}=$ volume de ácido sulfúrico $1 \mathrm{~N}$ utilizado, em $\mathrm{mL}$

$\mathrm{fc}=$ fator de correção do titulante

$\mathrm{m}=$ massa da amostra em gramas

\section{DETERMINAÇÃO DE CHUMBO POR GRAVIMETRIA}

Foi homogeneizado e transferido $25 \mathrm{~mL}$ da amostra previamente pesada para um tubo de centrífuga. Centrifugou-se, decantou-se e transferiu-se o líquido para um béquer de $250 \mathrm{~mL}$. Foi adicionado $25 \mathrm{~mL}$ de água no resíduo do tubo de centrífuga e agitou-se bem.

Foi centrifugado novamente e transferiu-se o líquido sobrenadante para o béquer de 250 $\mathrm{mL}$. Descartou-se o resíduo. Evaporou-se em banho-maria o líquido do béquer até a secura. Foi adicionado $20 \mathrm{~mL}$ de uma mistura de ácido sulfúrico e ácido nítrico, na proporção de 1:1. Cobriuse com um vidro de relógio e foi aquecendo em placa de aquecimento para oxidar possível matéria orgânica presente. Removeu-se o vidro de relógio para evaporar o trióxido de enxofre.

Esfriou-se e lavou-se os lados do béquer com água, cuidadosamente, e foi evaporado novamente o trióxido de enxofre. Deixou-se esfriar.

Adicionou $50 \mathrm{~mL}$ de água, cuidadosamente. Aqueceu quase à fervura e agitou até a solubilização de todo o sulfato de chumbo. Adicionou $75 \mathrm{~mL}$ de água e deixou em repouso por 1 hora, agitando ocasionalmente.

Com a mistura à temperatura ambiente, filtrou-se o precipitado em cadinho Gooch (de porcelana ou de vidro) e lavou-se cuidadosamente com uma solução de ácido sulfúrico (1:99). Calcinou-se o precipitado em mufla a 500-600드. até obter peso constante.

Os devidos cálculos foram realizados a partir da equação abaixo: 


$$
\mathrm{C}=\frac{M \times 0,6832 \times 100}{m}
$$

$$
\begin{aligned}
& C=\text { concentração }(p / p) \text { de chumbo } \\
& M=\text { massa do resíduo em gramas } \\
& m=\text { massa da amostra em gramas }
\end{aligned}
$$

\section{RESULTADOS}

Todos os resultados foram dispostos na forma de tabela e as amostras neste estudo representadas pelas letras de $A$ a $F$, por motivo de ética e preservação da imagem dos representantes comerciais. Os resultados, tanto para Amônia quanto para Chumbo, expressos em porcentagem foram necessários para obter resultados na mesma grandeza como é apresentado pela ANVISA.

Tabela 1. Resultados em \% do teor de Amônia disponível nas amostras.

\begin{tabular}{ccccc}
\hline Amostra & $\begin{array}{c}\text { Média Peso } \\
\text { Amostra }\end{array}$ & Média Vol. Ácido & $\begin{array}{c}\text { Concentração } \\
(\mathrm{p} / \mathrm{p})\end{array}$ & Resultado \% \\
\hline A & 1,0606 & 0,17 & 0,1447 & 0,14 \\
B & 1,0856 & 0,13 & 0,1080 & 0,11 \\
C & 1,0733 & 0,23 & 0,1934 & 0,19 \\
D & 1,0532 & 0,23 & 0,1971 & 0,20 \\
E & 1,0655 & 0,20 & 0,1694 & 0,17 \\
F & 1,0560 & 0,27 & 0,2308 & 0,23 \\
\hline
\end{tabular}

Fonte: Dados experimentais

Tabela 2. Resultados em \% do teor de Chumbo disponível nas amostras.

\begin{tabular}{cccccc}
\hline Amostra & Média tara & Média tara + resíduo & Resíduo & $\begin{array}{c}\text { Concentração } \\
(\mathrm{p} / \mathrm{p})\end{array}$ & Resultado \% \\
\hline A & 52,4080 & 52,4062 & 0,0018 & 0,00507 & 0,0074 \\
B & 51,0631 & 51,0569 & 0,0062 & 0,01743 & 0,0260 \\
C & 48,4510 & 48,5232 & 0,0722 & 0,19961 & 0,2900 \\
D & 53,2363 & 53,2346 & 0,0017 & 0,00466 & 0,0068 \\
E & 50,9095 & 50,9048 & 0,0047 & 0,01311 & 0,0190 \\
F & 51,4628 & 51,5095 & 0,0467 & 0,12652 & 0,1800 \\
\hline
\end{tabular}

\section{DISCUSSÃO}

Segundo a legislação vigente, o limite máximo permitido de Amônia não deve ultrapassar a $6 \%$, sendo que acima de $2 \%$ é obrigatório estar informado no rótulo que contém este tipo de substância.

Ao observar a Tabela 1, de maneira geral, as amostras não apresentaram valores acima de $2 \%$, por este motivo não se faz necessário constar a informação de presença de amônia nos rótulos. Foi observado na embalagem que o pouco de Amônia possivelmente presente nos resultados de cada amostra é porque consta a mesma na forma de Cloreto de Amônio. Observouse através da leitura da embalagem que a amônia estava presente na forma de cloreto de amônio.

Para o limite máximo permitido de Chumbo, segundo a ANVISA, não deve ser superior a 0,6\% ou 20ppm, sendo que nesta porcentagem a absorção cutânea é baixa.

Neste estudo foi possível quantificar quantitativamente o Chumbo por gravimetria e notar, de acordo com a Tabela 2, que todas as amostras estão abaixo do permitido pela legislação 
vigente. A não presença deste metal nas tinturas torna-se um produto seguro sem o risco de ocorrer possivelmente uma intoxicação tanto aguda e/ou crônica pelo metal Chumbo.

De maneira geral nenhuma amostra apresentou valores acima do estabelecido pela legislação vigente para Amônia e Chumbo. Desta forma, as tinturas em estudo apresentam-se de maneira segura quanto ao uso no dia a dia.

Um estudo por Hemielewski e da Silveira (2016), realizou-se análises de Chumbo e Amônia em tinturas capilares, utilizando o método titrimétrico para Amônia e método qualitativo de precipitação pra a presença de Chumbo. Como resultados não houve identificação de Chumbo em nenhuma das amostras, enquanto que Amônia foi apresentada um único resultado considerado por eles enganoso no mercado consumidor por ser apontada como uma tintura natural e apresentar-se $8,37 \%$ de Amônia em sua composição. Ainda que no presente estudo tenha sido resultados positivos para o consumidor, ainda percebe-se pelo estudo de Hemielewski e da Silveira (2016) que ainda existem produtos que são adulterados e que ainda chegam às prateleiras para uso final.

De Oliveira et al. (2014) realizou um estudo da possível toxicidade de tinturas capilares. Segundo os autores, estes estudos são baseados a partir de corantes permanentes ou com $p$ fenilanina e aminofenóis. Justifica-se esta preocupação porque se sabe que algumas aminas aromáticas são utilizadas na preparação e/ou formadas por degradação parcial dos corantes usados, ao qual são substâncias biologicamente ativas e que podem ser absorvidas percutaneamente, neste caso pode-se produzir efeitos mutagênicos ou carcinogênicos. Como conclusão os autores dizem que devido a grande oferta de produtos e a grande demanda de consumidores as avaliações destes compostos ainda são escassas e pouco difusas. Porém, neste estudo é observado que os efeitos crônicos podem ser piores do que se imagina levando em consideração o risco e câncer, desta forma a importância de um teste toxicológico torna-se ainda maior.

\section{CONCLUSÃO}

Conclui-se que as tinturas capilares de A a F estão em conformidade com a legislação vigente, portanto, podem ser classificadas como produtos seguros aos consumidores de maneira geral por não apresentarem teores de Amônia e Chumbo significativos a ponto de apresentarem qualquer risco para a saúde de acordo com o valor máximo permitido estabelecido pelo órgão fiscalizador, ANVISA.

Sugere-se como estudos futuros utilizando métodos analíticos instrumentais para possíveis novos resultados ou confirmações do presente estudo. Ainda como sugestão, submeter às amostras a testes toxicológicos para se certificar de que não apresentam riscos futuros mutagênicos ou carcinogênicos.

\section{REFERÊNCIAS BIBLIOGRÁFICAS}

ANVISA - Resolução 79, de 28/08/2000, Anexo III, Lista de Corantes Permitidos. Disponível em: <http://www.anvisa.gov.br/cosmeticos/guia/html/79_2000.pdf>. Acesso em: 04 ago. 2017.

ANVISA. Ensaios Analíticos - Identificação e doseamento. Disponível em: <http://www.anvisa.gov.br/cosmeticos/material/guia_cosmetico.pdf>. Acesso em 07 ago. 2017.

BARSANTI, L. Dr. Cabelo: saiba tudo sobre os cabelos: estética, recuperação capilar e prevenção da calvície. São Paulo: Editora Elevação, 2009. p. 27 e 28. 
DE OLIVEIRA, Ricardo AG et al. A química e toxicidade dos corantes de cabelo. Química Nova, p. 1037-1046, 2014.

GOMES, A. L. O uso da tecnologia cosmética no trabalho do profissional cabeleireiro. 4. ed. São Paulo: Editora Senac São Paulo, 1999. p. 115 e 116.

GOMES, R. K. Cosmetologia: descomplicando os princípios ativos. 4. ed. São Paulo: Livraria Médica Paulista Editora, 2013. p. 150 e 151.

HEMIELEWSKI, Caroline; DA SILVEIRA, Rosimar Leitenberg. Compostos nocivos ao organismo presentes em tonalizantes capilares. Disciplinarum Scientia| Saúde, v. 8, n. 1, p. 41-49, 2016.

KEDE \&SABATOVICH. Dermatologia Estética, 2009, 2. ed., Oleg Sabatovich, Maria Paulina Villarejo Kede, Editora Atheneu.

OLIVEIRA, R. A. G.; et al.A química e a toxicidade dos corantes de cabelo. v. 37, n. 6, maio, 2014.Disponível em: <http://quimicanova.sbq.org.br/imagebank/pdf/00b-sumario37-6.pdf>. Acesso em: 01 set. 2016. 